ISSN: 2224-0616

Int. J . Agril. Res. Innov. \& Tech. 4 (1): 57-63, June, 2014

Available online at http:// www.ijarit.webs.com

\title{
TOP SOIL SALINITY PREDICTION IN SOUTH-WESTERN PART OF URMIA LAKE WITH GROUND WATER DATA
}

\author{
N. Hamzehpour ${ }^{*}$, M.K. Eghbal'2, P. Bogaert ${ }^{3}$ and N. Toomanian4 \\ Received 13 February 2014, Revised 3 June 2014, Accepted 28 June 2014, Published online 30 June 2014
}

\begin{abstract}
Drying of Urmia Lake in the north-west of Iran threatens all the agricultural lands around the Lake. Therefore, soil salinity appears to be the major threat to the agricultural lands in the area. The aim of the present study was to investigate the spatial variation of top soil salinity by taking into account of underground water quality data as secondary information. The research was performed on a grid of $500 \mathrm{~m}$ in an area of 5000 ha. Soil samples were gathered during the autumn of 2009 and were repeated in the spring of 2010. Electrical conductivity of soil samples was measured in a 1:2.5 soil to water suspension. Then covariance functions were build for each data set and soil salinity prediction were done on a grid of $100 \mathrm{~m}$ using kriging estimator with taking into account the mean variation. Afterwards sodium activity ratio derived from underground water quality database was used as covariate to develop cross-semivarograms in prediction of top soil salinity using cokriging method. Results demonstrated that soil salinity varied from values lower than 0.5 to more than $35 \mathrm{dSm}^{-1}$ as a function of distance to the Lake. Cross-validating the results from salinity predictions using only kriging estimator to that of cokriging with sodium activity ratio data revealed that kriging offered better estimations with ME of 0.04 for autumn 2009 and -0.12 for spring 2010. Cokriging estimator had more smoother and diffused boundaries than that of kriging and resulted in more bias estimations $(\mathrm{ME}=-0.11$ and -0.21 for first and second data sets). Although kriging method had better performance in top soil salinity prediction, but cokring method resulted in smoother boundaries and reduced the negative effects of mean variation in the area.
\end{abstract}

Keywords: Urmia Lake, Electrical Conductivity, Sodium Activity Ratio, Cross-semi variogram

${ }^{1}$ Soil Science Department, Maragheh University, Maragheh, East Azerbaijan, Iran

${ }^{2}$ Soil Science Department, Tarbiat Modares University, Tehran, Iran

${ }^{3}$ Faculty of Bio-engineering, Agronomy and Environment, Catholic University of Leuven, Louvain-la-Neuve, Belgium

${ }^{4}$ Isfahan Research Centre for Agriculture and Natural Resources, Isfahan, Iran

*Corresponding author's email: nikooh62@yahoo.com (N. Hamzehpour)

\section{Introduction}

Urmia Lake is one of the biggest hyper saline lakes in the world and the biggest one in the Middle East, which is located in the north-west of Iran (Zarghami, 2011; Hassanzadeh et al., 2011). It is estimated that the surface area of the Lake was more than $6100 \mathrm{~km}$ in 1995, which has started to decrease rapidly since then (Eimanifar and Mohebbi, 2007).

Salinity of soils around Urmia Lake can be divided to two categories, lands, which are inherently and primarily salty, and areas affected by secondary salinization. Secondary salinization can occur due to the use of low quality saline irrigation water.

In order to manage salt affected soils, first it is required to monitor spatial variation of soil salinity to recognize regions with potential salinity and to prioritize the regions for temporal monitoring. Recent improvements in the field of geostatistics and advances in calculating complex problems have made the analysis of variables with spatial correlation possible. Kriging methods have widespread use in geostatistical methods and in soil salinity prediction models, which have been discussed in detail in several papers ( $\mathrm{Li}$ and Heap, 2008). There have been numerous attempts in mapping spatial variability of soil salinity using kriging methods (Peck and Hatton, 2003; Triantafilis et al., 2004; Malins and Metternicht, 2006; De Clercq et al., 2009; Giordano et al., 2010; Acosta et al., 2011; Li et al., 2011).

Stein and Corsten (1991) discussed the relationship between universal kriging and cokriging with regression kriging. Mondal et al. (2001) used linear and non-linear methods to predict top soil salinity in Bangladesh. De Clercq et al. (2009) utilized a first order polynomial 
equation for mapping spatial and temporal variation of soil salinity. Juan et al. (2011) took advantage of a spatial Gaussian linear mixed model to calculate soil salinity using soil electrical conductivity and Na content.

The aim of this research was to predict spatial variability of soil salinity in Urmia Plain, west of Urmia Lake, and to investigate possible effects of Urmia Lake dehydration on agricultural lands using underground water sodium activity ratio (SAR) as secondary information.

\section{Materials and Methods}

\section{Study site}

The region under investigation is located in the western part of Urmia Lake, north-west of Iran. It is located between $45^{\circ} 5^{\prime}$ to $45^{\circ} 20^{\prime} \mathrm{E}$ and $37^{\circ} 15^{\prime}$ to $37035^{\prime} \mathrm{N}$. The mean annual precipitation is $367 \mathrm{~mm}$. The mean annual temperature for the coldest month is $-5.2{ }^{\circ} \mathrm{C}$ and for the warmest one is $32{ }^{\circ} \mathrm{C}$. Potential evaporation in the area is between $900-1170 \mathrm{~mm}$. In terms of geology, the study area is composed of two different deposits: saline playa deposits and young alluvial terraces and alluvial fans with very low salinity.

\section{Soil salinity data set}

The location of the study area and sampling points are shown in Fig. 1. Soil samples were taken from depth $0-20 \mathrm{~cm}$ on a grid of 500 meter, once during autumn 2009 (first data set) and were repeated during spring 2010 (second data set). All soil samples were sieved and analyzed for their electrical conductivity (EC) in a 1:2.5 soil to water suspension.

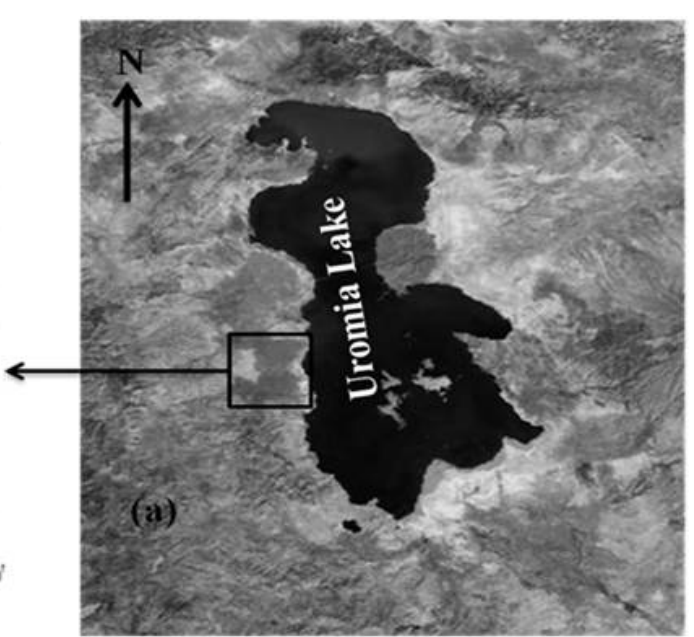

Fig. 1. Study area (a) and soil sampling locations (b) in west of Urmia Lake, North-west of Iran

\section{Underground water quality dataset}

In this study, underground water (UGW) quality analysis, which was available for seven years from 2001 to 2007, was utilized as secondary information in soil salinity prediction. These analyses included UGW electrical conductivity (EC), total dissolved salts (TDS), $\mathrm{pH}$, all common anions, and Cations (e.g. $\mathrm{CO}_{3}^{2-}, \mathrm{HCO}_{3}{ }^{-}, \mathrm{Cl}, \mathrm{K}^{+}$, $\mathrm{Na}^{+}$). Some other quality parameters like sodium activity ratio (SAR) were also calculated using equation 1.

$$
S A R=\frac{\sqrt{\left(C a^{2+}+M g^{2+}\right)}}{N a^{+}}
$$

Among aforementioned parameters, SAR values of UGW were spatially correlated with top soil salinity data set and consequently were chosen as covariate in soil salinity prediction.

\section{Covariance function}

Assuming random fields with spatial homogeneity, the mean function is constant:

$$
\mu_{x}(p)=\mu_{x}
$$

Hence, the covariance function can be written as follows:

$$
c_{x}(h)=E\left\{\left[Z(x)-\mu_{x}\right]\left[Z(x+h)-\mu_{x}\right]\right\}=E[Z(x) Z
$$

If the mean function is known, the moment's estimator of covariance function is:

$$
\hat{c}_{w}(h)=\frac{1}{N(h)} \sum_{i=1}^{N(h)}\{[z(x
$$

Where $\mathrm{N}(\mathrm{h})$ is the number of pairs of data separated by the spatial lag. 


\section{Cross-semivariance functions}

Kriging estimators' basic equation is defined as follows: (Li and Heap, 2008)

$Z\left(x_{i}\right)-\mu=\sum_{t=1}^{n} \lambda_{i}\left[Z\left(x_{i}\right)-\mu\left(x_{i}\right)\right.$

Equation 4 can be extended to incorporate the additional information to derive equation 5 as follows:

$$
\tilde{z}_{1}\left(x_{0}\right)-\mu_{1}=\sum_{i_{1}=1}^{n_{1}} \lambda_{i}\left[Z_{1}\left(x_{i_{1}}\right)-\mu_{1}\left(x_{i_{1}}\right)\right]+\sum_{j=2}^{n_{v}} \sum_{i_{j}=1}^{n_{j}} \lambda_{i_{j}}\left[Z_{j}\left(x_{i_{j}}\right)\right.
$$

Where $\mu_{1}$ is an acknowledged stationary mean of the primary variable, $Z_{1}\left(x_{i 1}\right)$ is the data at point $i_{1}$ $\mu_{1}\left(\mathrm{x}_{11}\right)$ is the mean of samples within the search window, $\mathrm{n}_{1}$ is the number of sample points within the search window for point $\mathrm{x}_{0}$ used to make the estimation, $\left(\lambda_{i 1}\right)$ is the weight selected to minimize the estimation variance of the primary variable, $\mathrm{n}_{\mathrm{v}}$ is the number of secondary variables, $n_{j}$ is the

The cross-semi variance can be estimated from data using the following equation:

$$
\hat{\gamma}_{12}(h)=\frac{1}{2 n} \sum_{i=1}^{n}\left[z_{1}\left(x_{i}\right)-z_{1}\left(x_{i}\right)-z_{1}\left(x_{i}+h\right)\right]\left[z_{2}\left(x_{i}\right)-\right.
$$

In the case of this research, $\mathrm{Z}_{1}$ refers to the soil salinity and $Z_{2}$ refers to the underground water SAR values, which can be possibly used as an indicator of soil salinity.

\section{Validation and comparison criteria}

In order to compare kriging with cokring method (SAR of ground water as covariate), two thirds of available data were used for modeling and the rest for comparing the two different models. Hence, three global performance criteria were computed: $r$, which is the Pearson correlation coefficient, the mean error (ME), and the mean squared error (MSE). Accurate predictions are thus characterized by a ME value that should be close to zero and a MSE that should be as small as possible.

All the analyses were done using the BMElib toolbox (Christakos et al., 2002) written using Matlab (MathWorks, 1999).

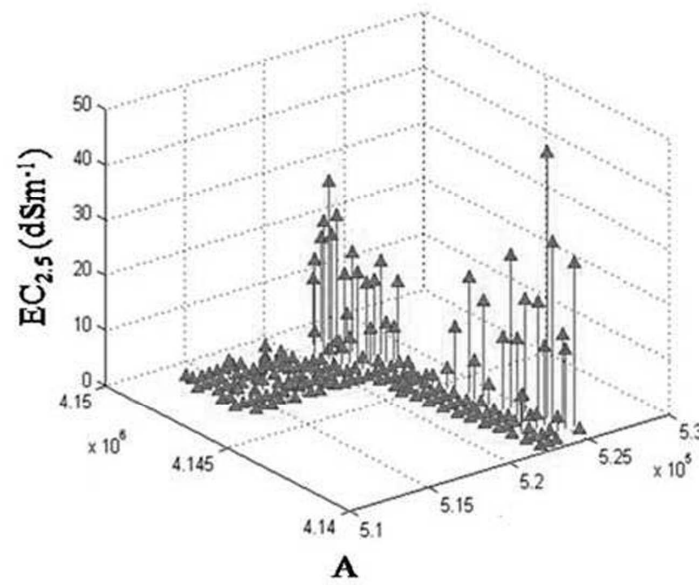

\section{Results and Discussion}

\section{Soil salinity data analyses}

Pole plots for top soil $\mathrm{EC}_{2.5}$ measurments during autumn 2009 and spring 2010 are presented in Fig. 2. The mean values for first and second data sets were $3.68 \mathrm{dSm}^{-1}$ and $4.73 \mathrm{dSm}^{-1}$, respectively. The increase of soil salinity mean value during spring 2010 was due to the seasonal variation of soil salinity, which is caused by rainfalls and water table fluctuations.

Soil salinity had a wide range of variation in the study area, from very low values (less than 0.5 $\mathrm{dSm}^{-1}$ ) in agricultural lands distant from Urmia Lake to very high values (more than $35 \mathrm{dSm}^{-1}$ ) in lands adjacent to the lake (Fig. 2).

Fig. 2. Pole plots for top soil (0-20 cm) EC2.5 laboratory measurements for autumn 2009 (A) and spring 2010 (B) 
On the basis of the obtained results, soil salinity variation was not gradual all over the study area, however there were sudden variations in an exact distance from Urmia Lake. This phenomina resulted in a big variation of soil salinity mean values around a boundary, which will be called soil salinity boundary afterwards.

Based on the geological information, the study area consists of two main deposits: saline playa deposits and young alluvial terraces and alluvial fans with very low salinity. The soil salinity boundary, where the main variation in soil salinity mean occurs, had a reasonable match with the geological boundaries. This means that spatial variation of soil salinity is also affected by geology

of the study area as well as the distance between samples.

\section{Underground water data analysis}

Color plots of UGW SAR values for seven years are displayed in Fig. 3. Temporal studies of these data showed that there was no significant variation in the SAR values of UGW from 2001 to 2007. This means that the quality of the UGW, which is being used for irrigation of the agricultural lands around the Urmia Lake, was not the main factor in secondary salinization of the lands through time. As the UGW SAR did not show significant temporal variation, mean of SAR data at each point of observation over years was taken to develop the covariance and crosssemivariance functions.

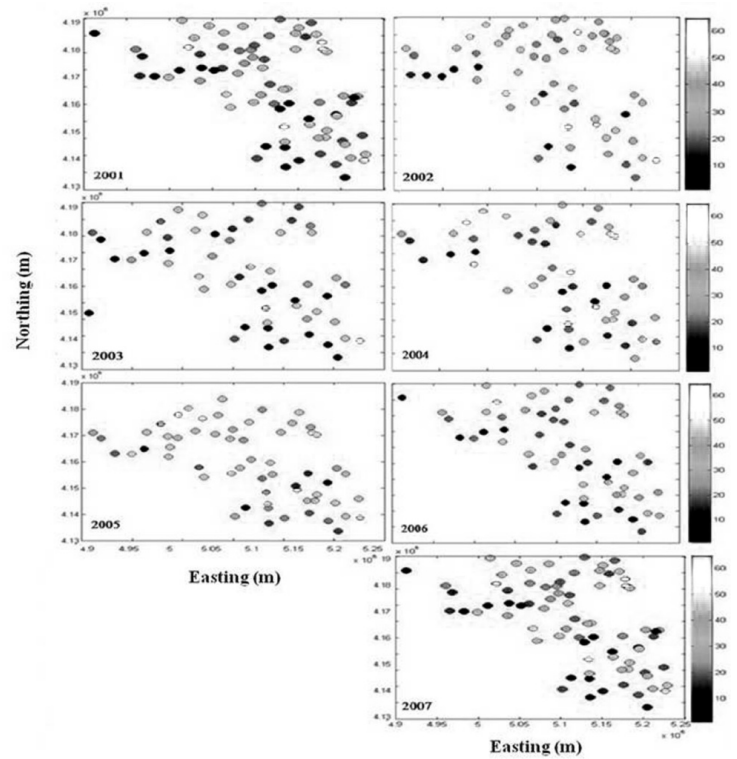

Fig.3. Color plots for the seven years underground water sodium activity ratio (SAR). The level of color reflects the SAR values in log scale.

\section{Covariance and Cross-semi variance functions}

As it was mentioned in previous sections, soil salinity had a variable mean throughout the study area. Therefore in order to consider the mean variation among datasets, the spatial components of the mean trend were computed and subtracted from measured $\mathrm{EC}_{2.5}$ values of both first and second datasets, which resulted in residuals. Then the covariance function for each dataset was calculated and modeled separately based on the residuals (Fig. 4 and 5, parts B).

Parameters of fitted covariance functions on soil salinity datasets during autumn 2009 and spring
2010 are presented in Table 1. The fitted covariance model for autumn 2009 had three parts: a nugget effect equal to $0.145\left(\mathrm{dS} \mathrm{m}^{-1}\right)^{2}$ and two spherical parts, consisting of a small scale component with sill of $2.31\left(\mathrm{dS} \mathrm{m}^{-1}\right)^{2}$ and spatial range of $2.5 \mathrm{~km}$, along with a larger scale component with sill of $0.01\left(\mathrm{dS} \mathrm{m}^{-1}\right)^{2}$ and spatial range of $5 \mathrm{~km}$ (Table 1). These results for spring 2010 were a nugget effect equal to 0.025 (dS m$\left.{ }^{1}\right)^{2}$ a small-scale component with sill of 2.57 (dS $\left.\mathrm{m}^{-1}\right)^{2}$ and spatial range of $2.5 \mathrm{~km}$ and a larger scale component with sill of $0.01\left(\mathrm{dS} \mathrm{m}^{-1}\right)^{2}$ and spatial range of $5 \mathrm{~km}$ (Table 1).

Table 1. Covariance functions parameters for first and second data sets

\begin{tabular}{lccc}
\hline $\begin{array}{l}\text { Covariance function } \\
\text { parameters }\end{array}$ & Nugget & $\begin{array}{c}\text { Small scale component sill } \\
(2.5 \mathrm{~km})\end{array}$ & $\begin{array}{c}\text { Large scale component sill } \\
(5 \mathrm{~km})\end{array}$ \\
\hline Autumn 2009 & 0.145 & 2.31 & 0.01 \\
Spring 2010 & 0.025 & 2.57 & 0.01 \\
\hline
\end{tabular}


In order to use UGW SAR in prediction of top soil salinity, the mean covariance function of available data for seven years was calculated and is shown in Fig. 4 and 5, parts A. Then cross-variograms were calculated using UGW SAR as covariate. The cross- variograms for first and second datasets are presented in Fig. 4 and 5, parts C, respectively.
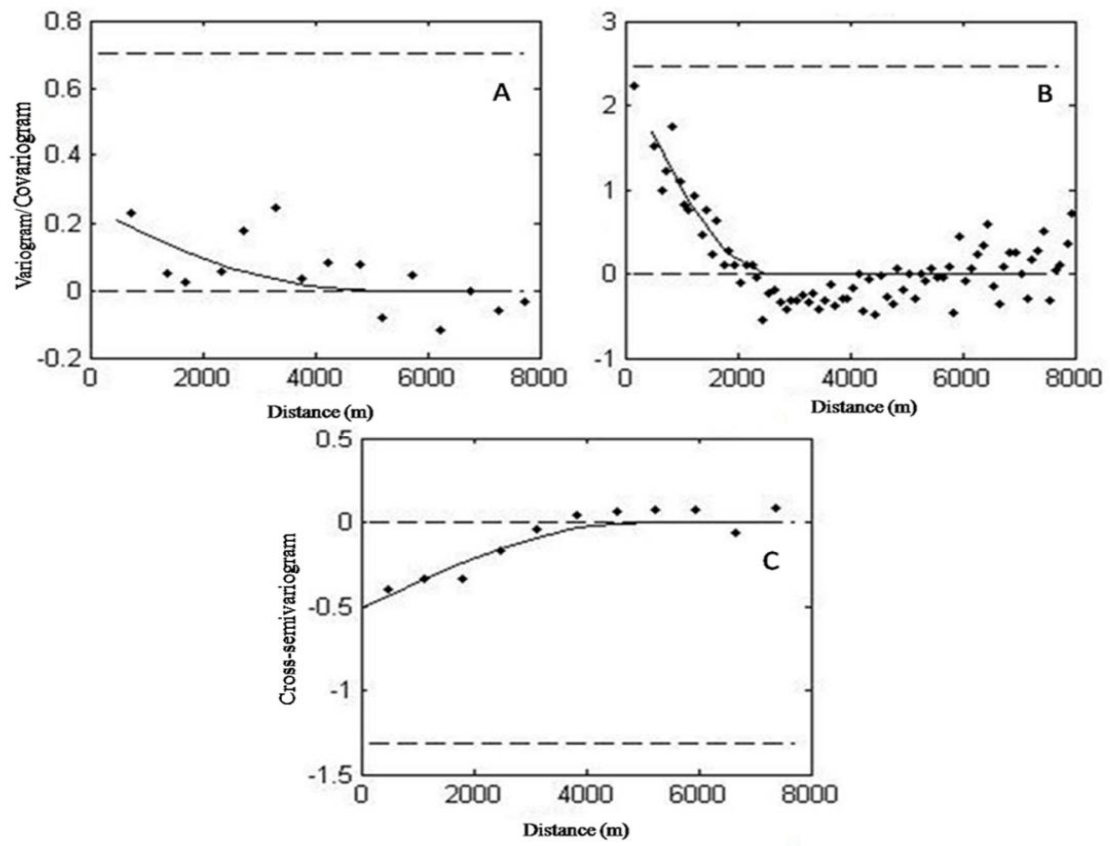

Fig. 4. Spatial covariance and cross-covariance functions for top soil salinity prediction during autumn 2009. A: covariance function for mean UGW SAR, B: covariance function for top soil $\mathrm{EC}_{2.5}$, and C: cross-covariance function for top soil $\mathrm{EC}_{2.5}$ using UGW SAR as covariate. Dots corresponds to estimated values, solid line is the corresponding fitted model.
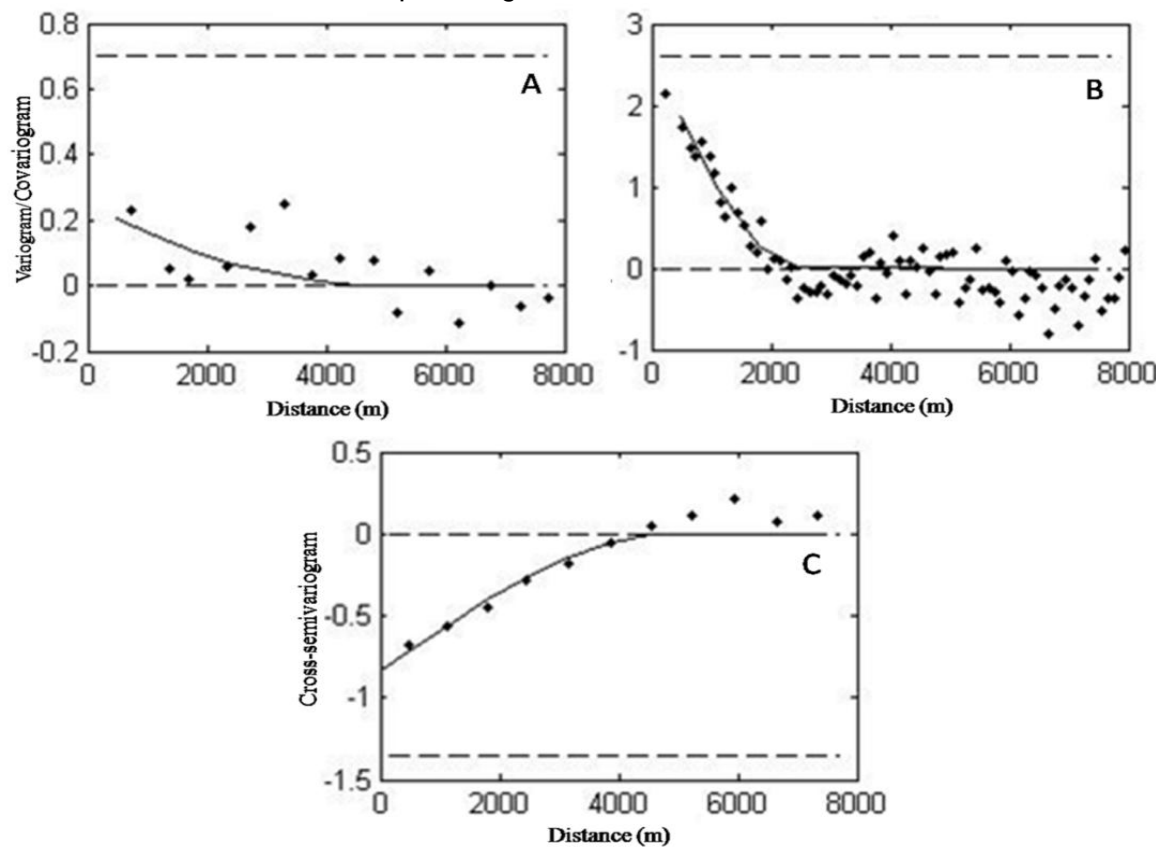

Fig. 5. Spatial covariance and cross-covariance functions for top soil salinity prediction during spring 2010. A: covariance function for mean UGW SAR, B: Covariance function for top soil $\mathrm{EC}_{2.5}$, and C: cross-covariance function for top soil $\mathrm{EC}_{2.5}$ using UGW SAR as covariate. Dots corresponds to estimated values, solid line is the corresponding fitted model. 


\section{Soil salinity prediction}

Soil salinity prediction maps for autumn 2009 and spring 2010 with only top soil $\mathrm{EC}_{2.5}$ data and UGW SAR data as covariate are shown in Figure 6. Comparing the cross-validation results from soil salinity predictions using only top soil $\mathrm{EC}_{2.5}$ data with those of UGW SAR as covariate indicated that the use of UGW SAR data as secondary information in top soil salinity prediction resulted in lower $\mathrm{r}$ and higher ME and MSE both for autumn 2009 and spring 2010. Higher negative $\mathrm{ME}$ values shows that the application of UGW SAR as covariate resulted in more under estimations of top soil salinity.

Table 2. Quantitative criteria to compare soil salinity prediction methods during autumn 2009 and spring 2010

\begin{tabular}{llclc}
\hline \multirow{2}{*}{ Criterion } & \multicolumn{3}{c}{ Autumn 2009} & \multicolumn{2}{c}{ Spring 2010 } \\
\cline { 2 - 5 } & $\mathrm{EC} 2.5$ & $\mathrm{EC}_{2.5} \& \mathrm{SAR}$ & $\mathrm{EC} 2.5$ & $\mathrm{EC}_{2.5} \& \mathrm{SAR}$ \\
\hline $\mathrm{r}$ & 0.94 & 0.87 & 0.92 & 0.85 \\
$\mathrm{ME}\left(\mathrm{dS} \mathrm{m}^{-1}\right)$ & 0.04 & -0.11 & -0.12 & -0.21 \\
$\operatorname{MSE}\left(\mathrm{dS} \mathrm{m}^{-1}\right)^{2}$ & 0.33 & 0.51 & 0.55 & 0.63 \\
\hline
\end{tabular}

In Fig. 6, parts B and D have smoother and more defuse bounders which, show that use of UGW SAR has homogenized the salinity variation with

removing the effect of mean variation in the study area within the range of $2.5 \mathrm{~km}$.
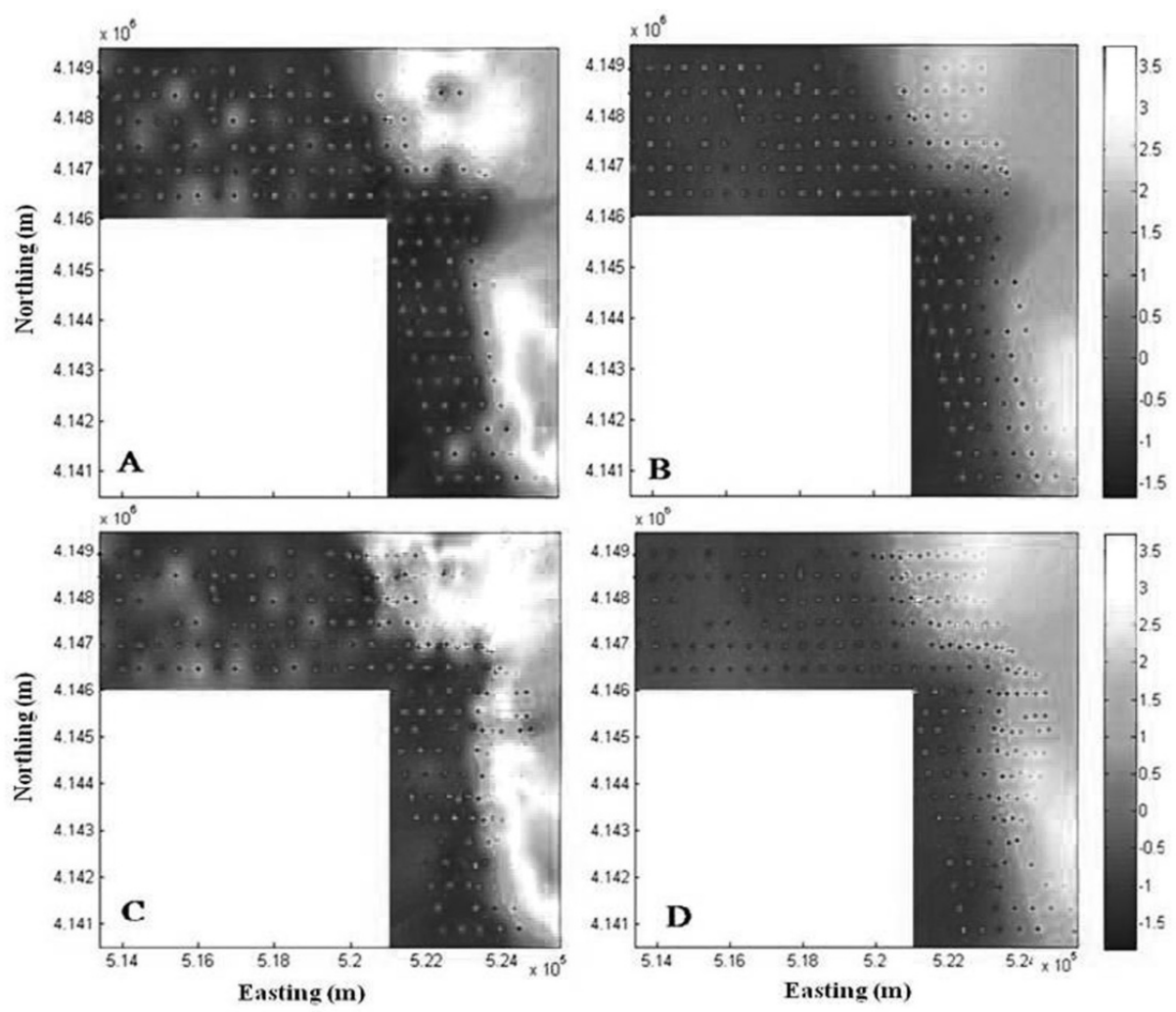

Fig. 6. Soil salinity prediction maps. A: soil salinity predictions for autumn 2009 with only top soil $\mathrm{EC}_{2.5}$ values; B: soil salinity predictions for autumn 2009 with UGW SAR as covariate; C: soil salinity predictions for spring 2010 with only top soil EC2.5 values, and D: soil salinity predictions for autumn 2009 with UGW SAR as covariate. Red points represent the places with top soil $\mathrm{EC}_{2.5}$ measurements.

\section{Conclusion}

This research was conducted to investigate the spatial variation of top soil salinity in Urmia Plain as a function of distance from Urmia Lake. Top soil EC2.5 measurements during autumn 2009 and spring 2010 and underground water SAR data for seven years were used to develop covariance and cross-semi variance functions. Results revealed that top soil salinity increased as distance from the Lake decreased. The increase in top soil salinity was not gradual and there was an instant 
increase in salinity data all around a boundary parallel to the Lake. To take into account the mean variation in kriging equations, some assumptions were made and soil salinity was predicted on a $100 \mathrm{~m}$ grid. Afterwards as there was no significant temporal variation in UGW SAR data, the mean SAR data over time were used to develop the cross-semivariograms. Salinity predictions maps using cross-semivariograms and cokriging method showed that the use of UGW SAR data as covariate had a smoothing effect on $\mathrm{EC}_{2.5}$ covariance functions and produced more diffused and gradual soil salinity boundaries, which resulted in more underestimations (higher $\mathrm{ME})$ than that of kriging.

\section{References}

Acosta, J .A., Faz, A., Jansen, B., Kalbitz, K. and Martinez-Martinez, S. 2011. Assessment of salinity status in intensively cultivated soils under semiarid climate, Murcia, SE Spain. J. Arid Environ. 75: 1056-1066.

Christakos, G., Bogaert, P. and Serre, M.L. 2002. Temporal GIS. Advanced Functions for Field-Based Applications. Springer-Verlag, New York.

De Clercq, W.P., Van Meirvenn, M. and Fey, M.V. 2009. Prediction of the soil-depth salinitytrend in a vineyard after sustained irrigation with saline water. Agril. Water Manag. 96: 395-404.

Eimanifar, A. and Mohebbi, F. 2007. Uromia Lake (Northwest Iran): a brief review. Saline Systems 3: 5. doi:10.1186/ 1746-1448-3-5.

Giordano, R., Liersch, S., Vurro, M. and Hirsch, D. 2010. Integrating local and technical knowledge to support soil salinity monitoring in the Amudarya river basin. J. Environ. Manag. 91: 1718-1729.

Hassanzadeh, E., Zarghami, M. and Hassanzadeh, Y. 2011. Determining the main factor in declining the Uromia Lake level by using
System Dynamics Modeling. Water Resources Manag. 26 (1): 129-145.

Juan, P., Mateu, J., Jordan, M.M., MataixSolera, J., Melendez-Pastor, I. and NavarroPedreno, J. 2011. Geostatistical methods to identify and map spatial variations od soil salinity. J. Geochem. Explor. 108: 62-72.

Li, J. and Heap, A.D. 2008. A Review of Spatial Interpolation Methods for Environmental Scientists. Geoscience Australia, Canberra, Australia.

Li, K.L., Chen, J., Tan, M.Z, Zhao, B.Z., Mi, S.X. and Shi, X.Z. 2011 Spatio-Temporal variability of soil salinity in Alluvial Plain of the lower reaches of the Yellow River- a case study. Pedosphere 21 (6): 793-801.

Malins, D. and Metternicht, G. 2006. Assessing the spatial extent of dry land salinity through fuzzy modeling. Ecological Modelling 193: 387-411.

Math Works Inc. 1998. MatLab, the language of technical computing, using MATLAB version 5. the Mathwork Inc. http://www.mathworks.com, Natick.

Mondal, M.K., Bhuiyan, S.I. and Franco, D.T. 2001. Soil salinity reduction and prediction of salt dynamics in the coastal rice lands of Bangladesh. Agril. Water Manag. 47: 9-23.

Peck, A.J. and Hatton, T. 2003. Salinity and the discharge of salts from catchments in Aus. J. Hydrol. 272: 191-202.

Stein, A. and Corsten, L.C.A. 1991. Universal kriging and cokriging as a regression procedure. Biometrics 47: 575- 587.

Triantafilis, J., Odeh, I.O.A., Warr, B. and Ahmed, M.F. 2004. Mapping of salinity risk in the lower Namoi valley using non-linear kriging methods. Agril. Water Manag. 69: 203-231.

Zarghami, M. 2011. Effective watershed management; Case study of Urmia Lake, Iran. Lake and Reservoir Manag. 27 (1): 87-94. 